\title{
Commentary \\ Deficient mitochondrial biogenesis in critical illness: cause, effect, or epiphenomenon?
}

\author{
Richard J Levy ${ }^{1}$ and Clifford S Deutschman ${ }^{2}$
}

\begin{abstract}
${ }^{1}$ Maria Fareri Children's Hospital of Westchester Medical Center, New York Medical College, Valhalla, New York, USA
2Department of Anesthesiology and Critical Care and the Stavropoulos Sepsis Research Program, University of Pennsylvania School of Medicine, Philadelphia, Pennsylvania, USA
\end{abstract}

Corresponding author: Clifford S Deutschman, deutschcl@uphs.upenn.edu

Published: 24 August 2007

This article is online at http://ccforum.com/content/11/4/158

(c) 2007 BioMed Central Ltd

See related research by Côté et al., http://ccforum.com/content/11/4/R88
Critical Care 2007, 11:158 (doi:10.1186/cc6098)

conclude that loss or failed synthesis of mtDNA is a unifying cause of sepsis-induced mitochondrial dysfunction and that clinicians could use mtDNA copy number to predict mortality during critical illness. This requires a more detailed examination of mtDNA heterogeneity and mitochondrial regeneration.

Each mitochondrion has 2-10 copies of its own circular genome. These encode for 13 essential subunits of electron transport chain enzymes, two ribosomal RNAs and 22 transfer RNAs [7]. The structural subunits of the electron transport complexes and other mitochondrial proteins arise from nuclear genes [8]. Thus, expression of the genes encoding mitochondrial enzyme complexes is under dual control. mtDNA is particularly prone to deletions, rearrangements and mutations caused by oxidative stress because it is unbound by histones and because these organelles lack the extensive repair systems seen in the nucleus [9]. Therefore, reactive oxygen species produced during oxidative phosphorylation in a variety of disease states can damage mtDNA and mitochondrial proteins. This would lead to decreased ATP production and enhanced programmed cell death [7].

Heteroplasmy describes the coexistence of both mutant mtDNA and wild-type, non-mutant mtDNA within the same cell [8]. If the mitochondrial genome drift results in a significant amount of mutant mtDNA, cells exhibit reduced energy capacity and organs become dysfunctional [7]. The threshold for these processes is lower in highly oxidative tissue such as brain, heart, skeletal muscle, retina, kidney and endocrine organs [8]. This threshold effect explains tissue-related variability in the clinical presentation of both inherited and acquired mitochondrial diseases [8]. 
Impaired mitochondrial biogenesis represents an additional manner in which mitochondria may contribute to acquired disorders. Biogenesis includes all of the processes needed for mitochondrial homeostasis and division. It requires precise coordination between both mitochondrial and nuclearencoded gene products as well as maintenance and replication of mtDNA $[10,11]$. Recent investigation demonstrates that experimental murine sepsis caused mitochondrial oxidative stress, a loss of mtDNA copy number and depressed basal metabolism in the septic liver [12]. In the recovery phase, mitochondrial biogenesis restored mtDNA copy number and oxidative metabolism.

Our understanding of bioenergetic failure in sepsis and shock has been largely limited by interpretation of early investigations. These studies assumed that preservation of cellular ATP indicated intact electron transport [13,14]. However, more recent data make it clear that cells can adapt and maintain viability by down-regulating oxygen consumption, energy requirements and ATP demand $[15,16]$. In the heart this response is called myocardial hibernation and results in cardiomyocyte hypocontractility with preserved cellular ATP [15]. Hibernating cells maintain ATP levels in the setting of defective oxidative phosphorylation by ceasing nonessential cellular functions to limit ATP utilization $[15,16]$. At the organ level, this down-regulated metabolic state may manifest as "organ dysfunction" or "organ failure". During hypoxia, ischemia and in early or non-fatal sepsis, such a response appears to be adaptive and often reversible as cells at risk maintain viability and recover after reoxygenation and reperfusion. Our data, however, indicate that during lethal sepsis a similar hibernation response, while initially adaptive, may become problematic as cells remain persistently downregulated, enzyme complex content and activity decrease and organ failure becomes irreversible $[3,4]$. This may result from an acquired defect in gene expression and/or functional activity of any of the electron transport enzymes [17]. Our data suggest that persistently impaired mitochondrial gene expression may represent the irreversible defect that leads to organ failure and death.

The hypothesis that therapeutically enhancing mitochondrial biogenesis could improve survival is fascinating, especially if defects in mitochondrial replication and mtDNA synthesis also occur in cells of solid organs. Based on recent reports, it is conceivable that stem cells or fibroblasts may be able to restore defective mitochondria in neighboring cells with wildtype mtDNA [18]. Thus, future investigation should focus on increasing and restoring wild-type mtDNA to restore cellular oxidative capacity and organ function in sepsis and shock.

What is most exciting is that we are still gaining insight into this billion year old, complex organelle. However, it remains unclear if mitochondrial impairment causes organ dysfunction, is protective against impending organ injury or is an epiphenomenon. The data presented to date have not directly addressed this issue. These questions demand a more exhaustive investigation of the fascinating processes of mitochondrial biogenesis and homeostasis during both health and disease.

\section{Competing interests}

The authors' work is supported by NIH/NIGMS 1K08GM074117 (RJL), Maria Fareri Children's Hospital Foundation Grant (RJL), NIH/NIGMS 5R01GM059930 (CSD).

\section{References}

1. Côté HCF, Day AG, Heyland DK: Longitudinal increases in blood cells mitochondrial DNA levels are associated with survival in critically ill patients. Crit Care 2007, 11:R88.

2. Wallace DC: A mitochondrial paradigm of metabolic and degenerative diseases, aging, and cancer: a dawn for evolutionary medicine. Annu Rev Genet 2005, 39:359-407.

3. Brealey D, Singer M: Mitochondrial dysfunction in sepsis. Curr Infect Dis Rep 2003, 5:365-371.

4. Levy RJ, Vijayasarathy, C, Raj NR, Avadhani, NG, Deutschman, CS: Competitive and noncompetitive inhibition of myocardial cytochrome C oxidase in sepsis. Shock 2004, 21:110-114.

5. Levy RJ, Piel DA, Acton PD, Zhou R, Ferrari VA, Karp JS, Deutschman CS: Evidence of myocardial hibernation in the septic heart. Crit Care Med 2005, 33:2752-2756.

6. Piel DA, Gruber PJ, Weinheimer CJ, Courtois MR, Robertson CM, Coopersmith CM, Deutschman CS, Levy RJ: Mitochondrial resuscitation with exogenous cytochrome $c$ in the septic heart Crit Care Med, in press.

7. Wallace DC: Mitochondrial diseases in man and mouse. Science 1999, 283:1482-8.

8. DiMauro S, Schon EA: Mitochondrial respiratory-chain diseases. N Engl J Med 2003, 348:2656-68.

9. Richter C, Park JW, Ames BN: Normal oxidative damage to mitochondrial and nuclear DNA is extensive. Proc Natl Acad Sci U S A 1988, 85:6465-7.

10. Lee $\mathrm{HC}$, Wei $\mathrm{YH}$ : Mitochondrial biogenesis and mitochondrial DNA maintenance of mammalian cells under oxidative stress. Int J Biochem Cell Biol 2005, 37:822-34.

11. Cotney J, Wang Z, Shadel GS: Relative abundance of the human mitochondrial transcription system and distinct roles for h-mtTFB1 and h-mtTFB2 in mitochondrial biogenesis and gene expression. Nucleic Acids Res 2007, 35:4042-54.

12. Haden DW, Suliman HB, Carraway MS, Welty-Wolf KE, Ali AS, Shitara H, Yonekawa H, Piantadosi CA: Mitochondrial biogenesis restores oxidative metabolism during staphylococcus aureus sepsis. Am J Respir Crit Care Med, in press.

13. Solomon MA, Correa R, Alexander HR, Koev LA, Cobb JP, Kim DK, Roberts WC, Quezado ZM, Scholz TD, Cunnion RE et al:: Myocardial energy metabolism and morphology in a canine model of sepsis. Am J Physiol 1994, 266:H757-68.

14. Hotchkiss RS, Song SK, Neil JJ, Chen RD, Manchester JK, Karl IE, Lowry $\mathrm{OH}$, Ackerman JJ: Sepsis does not impair tricarboxylic acid cycle in the heart. Am J Physiol 1991, 260:C50-57.

15. Budinger, GR, Duranteau, J, Chandel, NS, Schumacker, PT: Hibernation during hypoxia in cardiomyocytes. Role of mitochondria as the O2 sensor. J Biol Chem 1998, 273:3320-3326.

16. Schumacker PT, Chandel N, Agusti AG: Oxygen conformance of cellular respiration in hepatocytes. Am J Physiol 1993, 265: L395-402.

17. Fink MP: Bench-to-bedside review: cytopathic hypoxia. Critical Care 2002, 6:491-499.

18. Spees JL, Olson SD, Whitney MJ, Prockop DJ: Mitochondrial transfer between cells can rescue aerobic respiration. Proc Natl Acad Sci U S A 2006, 103:1283-8. 